\section{Primeira avaliação do cumprimento dos "Dez Passos para o Sucesso do Aleitamento Materno" nos Hospitais Amigos da Criança do Brasil}

\author{
First assessment of the "Ten Steps for the \\ Maternal Breast-Feeding Success" \\ compliance in Baby-Friendly Hospitals in \\ Brazil
}

Maria de Fátima Moura de Araújo 1

Ana Flávia Nascimento Otto 2

Bethsáida de Abreu Soares Schmitz 3

1-2 Ministério da Saúde. Esplanada dos Ministérios, Bloco G, Anexo, $3^{\circ}$ andar. Brasília, DF, Brasil. CEP: 70.058-900. E-mail: fmarujo@tba.com.br

3 Universidade de Brasília. Faculdade de Ciências da Saúde. Departamento de Nutrição. Brasília, DF. Brasil.

\begin{abstract}
Objectives: to assess compliance of the "Ten Steps towards Maternal Breast-Feeding Success" in "Child Friendly Hospitals" (CFH) in Brazil.

Methods: assessment of the 10 steps of $\mathrm{CFH}$ was accomplished in 1999 and 2000 by evaluators of the CFH Initiative, accredited by the Ministry of Health through the pre-assessment form CFHI form.

Results: one hundred and thirty seven $\mathrm{CFH}$ questionnaires of 152 of accredited Child Friendly Hospitals were analized and $92 \%$ of them met all of the "Ten Steps..." Steps one, three, seven, eight and nine had compliance rates of over $98 \%$. Step five was the least observed. Comparing the regions of the country, it was noted that in the Northeast, South and Southeast, 90\% of the hospitals were approved in all of the "Ten Steps..." In the Northern region, only 50\% of the hospitals complied with all of the "Ten Steps..."

Conclusions: analysis of the general data sheet of the hospitals with shortcomings in the assessment of the steps, indicated that 73,7\% had been accredited before 1997 which is suggestive of the need of periodic evaluations. The implementation of a monitoring system for this type of institution will contribute to improve service quality and rates of breastfeeding in the country.
\end{abstract}

Key words Evaluation, Hospitals, Breast feeding

\section{Resumo}

Objetivos: avaliar o cumprimento dos "Dez Passos para o Sucesso do Aleitamento Materno" nos hospitais "Amigos da Criança" (HAC) no Brasil.

Métodos: estudo descritivo transversal de avaliação dos "Dez Passos..." dos HAC, realizado nos anos de 1999 e 2000, por avaliadores da Iniciativa Hospital Amigo da Criança (IHAC), credenciados pelo Ministério da Saúde, usando o formulário de préavaliação da IHAC.

Resultados: foram analisados os questionários de 137 HAC (90\%) do total de 152 HAC credenciados na época no país. Observou-se que $92 \%$ dos HAC atenderam todos os "Dez Passos..." Os passos um, três, seis, sete, oito e nove apresentaram mais de $98 \%$ de cumprimento. $O$ passo cinco foi o menos atendido. Comparando as regiões do país, observou-se que, no Nordeste, no Sul e no Sudeste, 90\% dos hospitais foram aprovados em todos os "Dez Passos..." Na região Norte, apenas $50 \%$ dos hospitais cumpriram todos os "Dez Passos..."

Conclusões: analisando a folha de dados gerais dos hospitais com pendências na avaliação dos passos, observa-se que 73,7\% foram credenciados antes de 1997, sugerindo a necessidade de avaliações periódicas. A implantação de um sistema de monitoramento dessa iniciativa, contribuirá para a melhoria da qualidade da assistência e dos índices de aleitamento materno no país.

Palavras-chave Avaliação, Hospitais, Aleitamento materno 


\section{Introdução}

A Iniciativa Hospital Amigo da Criança (IHAC) é uma ação mundial, idealizada, em 1990, pelo Fundo das Nações Unidas para a Infância (UNICEF) e pela Organização Mundial da Saúde (OMS), que visa promover, proteger e apoiar a prática do aleitamento materno, a fim de reduzir o desmame precoce e suas conseqüências sobre a morbi-mortalidade infantil. ${ }^{1}$

Essa estratégia foi criada para promover a implementação da segunda meta da Declaração de Innocenti ${ }^{2}$ de assegurar a prática dos "Dez Passos ..." para o sucesso no aleitamento materno, estabelecidos na declaração conjunta OMS e UNICEF, em todos os estabelecimentos que ofereçam serviços de maternidade. Também buscou atender os aspectos da terceira meta operacional, relativos aos estabelecimentos de saúde, para que efetivem os princípios e os objetivos dos artigos do Código Internacional de Comercialização dos Substitutos do Leite Materno e das subseqüentes resoluções relevantes da Assembléia Mundial de Saúde, citadas pela OMS.2,3

Para que uma maternidade ou um hospital, com leitos obstétricos, se transforme em um "Hospital Amigo da Criança", faz-se necessário, portanto, mobilizar funcionários e profissionais de saúde, no intuito de gerar mudanças em condutas e rotinas existentes, visando prevenir o desmame precoce. 4,5

O desmame precoce é resultado de uma complexa interação de fatores socioculturais, como por exemplo, o processo de industrialização, o surgimento e a divulgação de leites industrializados, com a respectiva adesão de profissionais de saúde à prescrição da alimentação artificial, a inserção da mulher no trabalho, e a adoção nas Maternidades de medidas pouco incentivadoras do aleitamento materno. 6

Com vistas à redução do desmame precoce, e com base na modificação de rotinas hospitalares inadequadas à prática da amamentação, foram normatizadas pela OMS e UNICEF as orientações abaixo, denominadas dos "Dez Passos para o Sucesso do Aleitamento Materno".2,5

1.Ter uma norma escrita sobre aleitamento materno, que deverá ser rotineiramente transmitida a toda a equipe de cuidados de saúde;

2. Treinar toda a equipe de cuidados de saúde, capacitando-a para implementar esta norma;

3. Informar todas as gestantes sobre as vantagens e o manejo do aleitamento;

4. Ajudar as mães a iniciar a amamentação na primeira meia-hora após o parto;

5. Mostrar às mães como amamentar e como manter a lactação, mesmo se vierem a ser separadas de seus filhos;
6. Não dar a recém-nascidos nenhum outro alimento ou bebida além do leite materno, a não ser que seja indicado pelo médico;

7. Praticar o alojamento conjunto - permitir que as mães e os bebês permaneçam juntos 24 horas por dia;

8. Encorajar o aleitamento sob livre demanda;

9. Não dar bicos artificiais ou chupetas a crianças amamentadas ao seio;

10. Encorajar a formação de grupos de apoio à amamentação para onde as mães devem ser encaminhadas, logo após a alta do hospital ou do ambulatório.

Essa iniciativa conta com a adesão de cerca de 130 países tendo credenciado, até dezembro de 2002, 257 hospitais no Brasil e mais de 18.000 hospitais em todo mundo. 7

Em 1992, o Ministério da Saúde e o Grupo de Defesa da Saúde da Criança, com o apoio do UNICEF e da Organização Pan-Americana de Saúde (OPAS), iniciaram a implantação da IHAC no Brasil, credenciando, em Recife, PE, o primeiro Hospital Amigo da Criança: o Instituto Materno Infantil de Pernambuco (IMIP). 8

Em todo o mundo para que um hospital receba o título de "Amigo da Criança", ele deve cumprir todos os "Dez Passos..." O processo de credenciamento inicia-se com o preenchimento, pelo hospital, do questionário de auto-avaliação, que deverá ser encaminhado à área competente da Secretaria Estadual de Saúde (SES) para análise. Após esta etapa, a SES designa um avaliador da IHAC para realizar a préavaliação. Quando o hospital é aprovado no processo de pré-avaliação, a SES solicita ao Ministério da Saúde a avaliação global da unidade, que por sua vez, encaminha dois avaliadores externos para realizar o procedimento. O credenciamento acontece, no Brasil, quando a unidade cumpre, na avaliação global, os "Dez Passos..." e mais cinco pré- requisitos. ${ }^{9}$

Diferentemente dos demais países do mundo, no Brasil, no final de 1996, o Programa Nacional de Incentivo ao Aleitamento Materno vinculado ao Instituto Nacional de Alimentação e Nutrição (INAN), estabeleceu, por meio de ofício circular encaminhado as SES, cinco pré-requisitos, indicadores da qualidade da assistência à mulher e à criança, no processo de avaliação, a saber: 1) Não estar respondendo a processo judicial relativo à assistência prestada e ou sindicância do Sistema Único de Saúde (SUS); 2) Dispor de responsável médico habilitado para assistência ao binômio mãe-filho na maternidade e sala de parto; 3) Apresentar taxa de mortalidade materna intra-hospitalar menor ou igual a 70/100.000 nascidos vivos, excluídas nos hospitais de referência as pacientes encaminhadas de outras instituições; 4) Apre- 
sentar taxa de cesariana menor ou igual a $30 \%$ para hospitais gerais e menor ou igual a $40 \%$ para hospitais de referência; 5) Apresentar tempo de permanência hospitalar de no mínimo 24 horas para pacientes de parto normal e de 48 horas para pacientes de parto cesariano. 5

Cabe ainda ressaltar, que apenas no Brasil, os "Hospitais Amigo da Criança" recebem incentivo financeiro, pagos pelo Ministério da Saúde, sobre os procedimentos obstétricos realizados nos mesmos. 10

Devido à inexistência, até então, de um sistema de monitoramento dos HAC no Brasil, a Área Técnica de Aleitamento Materno da Saúde da Criança do Ministério da Saúde, por meio de denúncias, tomou conhecimento de que alguns hospitais estavam deixando de cumprir alguns dos passos da "Iniciativa" ao longo dos anos. Para que essa situação fosse controlada, foi planejada a primeira avaliação dos HAC, para se verificar o cumprimento dos "Dez Passos...", nos hospitais credenciados.

O objetivo desse monitoramento foi implantar um sistema de avaliação periódica nessas instituições, o que sem dúvida é de fundamental importância para garantir a qualidade da assistência prestada por meio da "Iniciativa Hospital Amigo da Criança".

\section{Métodos}

Esse é um estudo descritivo transversal, onde os dados foram coletados por avaliadores credenciados pelo Ministério da Saúde, no período de outubro de 1999 a abril de 2000, utilizando-se o formulário de Pré-avaliação da "Iniciativa Hospital Amigo da Criança". Esse formulário foi aplicado a 137 instituições credenciadas, o que correspondia a $90 \%$ do total de 152 HAC credenciados no país, à época do estudo.

O instrumento de pré-avaliação foi utilizado por não existir, até a ocasião, um formulário apropriado para o processo de monitoramento desses hospitais. Esse formulário tem sido aplicado pelas Secretarias Estaduais de Saúde na etapa inicial do processo de avaliação dos hospitais candidatos ao credenciamento na IHAC. Trata-se de um instrumento simplificado de avaliação dessas unidades, que utiliza uma amostra reduzida de entrevistados, quando comparado com o processo de avaliação global.

Ele foi estruturado a partir do questionário de avaliação global de hospitais. Os profissionais de saúde, as gestantes e mães entrevistadas foram selecionados segundo plano de amostragem aleatória. Para este estudo ficou determinado que a amostra a ser entrevistada seria formada por cinco gestantes, cinco puérperas (sendo três de partos normais e duas de parto cesariano) e cinco funcionários da equipe de saúde que cuida das mães e bebês nas unidades de pré e pós-parto.

O formulário de pré-avaliação de hospitais, compreende 32 questões, que avaliam o cumprimento dos "Dez passos..." da IHAC, nas enfermarias da maternidade e nos serviços de pré-natal, utilizando perguntas objetivas, de respostas afirmativas ou negativas. Para cada passo, há um conjunto de perguntas, que devem ser respondidas corretamente por, no mínimo, $80 \%$ dos entrevistados, para que o item seja considerado cumprido.

Coube às Secretarias Estaduais de Saúde designar dois avaliadores do estado, credenciados pelo Ministério da Saúde, para aplicar o formulário nas instituições credenciadas de sua região, não podendo ser indicado profissional que tivesse qualquer tipo de envolvimento com o hospital a ser avaliado.

Os passos foram classificados como "cumprido" ou "não cumprido". Os resultados foram distribuídos por estado, região e país, sendo apresentados na forma de figuras e tabelas, expressos em porcentagem e números absolutos. O programa utilizado para tabulação dos dados foi o Microsoft Excel.

Foi estabelecido que o hospital que não cumprisse de um a seis passos, passaria por uma reavaliação dos passos pendentes, no período de três a seis meses, a contar da data do anúncio oficial, pelo Ministério da Saúde, dos resultados da avaliação. O não cumprimento de mais de seis passos, acarretaria no descredenciamento do hospital, o qual poderia submeter-se a nova avaliação global pelo Ministério da Saúde, após posterior adequação de suas condutas e rotinas.

\section{Resultados}

Foram analisados os formulários de 137 instituições, totalizando 90\% dos "Hospitais Amigo da Criança" credenciados na época no país. Todos os HAC situados nas regiões Centro-Oeste e Sudeste foram avaliados. As regiões Nordeste, Norte e Sul tiveram o percentual de $86 \%, 50 \%$ e $95 \%$, respectivamente, de hospitais avaliados. Os estados de Alagoas e Sergipe não avaliaram seus HAC.

Os resultados desse estudo revelaram que $92 \%$ dos HAC do Brasil $(n=126)$ cumpriam todos os "Dez Passos..." Analisando o comportamento de cada um dos passos, observa-se, na Tabela 1, que os mais cumpridos foram os passos um, três, seis, sete, oito e nove, todos com cumprimento superior a $98 \%$. O passo menos cumprido foi o passo cinco, seguido dos passos dez e dois respectivamente. 
Tabela 1.

Número de hospitais* conforme cumprimento dos "Dez Passos para o Sucesso do Aleitamento Materno", no Brasil, de 1999 a 2000.

\begin{tabular}{ccccccccccccc}
\hline Passos & $\mathbf{1}$ & $\mathbf{2}$ & $\mathbf{3}$ & $\mathbf{4}$ & $\mathbf{5}$ & $\mathbf{6}$ & $\mathbf{7}$ & $\mathbf{8}$ & $\mathbf{9}$ & & & \\
\hline $\mathrm{n}$ & 134 & 130 & 134 & 132 & 126 & 134 & 136 & 134 & 136 & 127 \\
$\%$ & 98,0 & 95,0 & 98,0 & 96,0 & 92,0 & 98,0 & 99,0 & 98,0 & 99,0 & 93,0 \\
\hline
\end{tabular}

* Total de Hospitais Amigos da Criança avaliados: 137.

Passo 1. Ter uma norma escrita sobre aleitamento materno, que deverá ser rotineiramente transmitida a toda a equipe de cuidados de saúde; Passo 2. Treinar toda a equipe de cuidados de saúde, capacitando-a para implementar esta norma; Passo 3 . Informar todas as gestantes sobre as vantagens e o manejo do aleitamento; Passo 4. Ajudar as mães a iniciar a amamentação na primeira meia-hora após o parto; Passo 5. Mostrar às mães como amamentar e como manter a lactação, mesmo se vierem a ser separadas de seus filhos; Passo 6. Não dar a recém-nascidos nenhum outro alimento ou bebida além do leite materno, a não ser que seja indicado pelo médico; Passo 7 . Praticar o alojamento conjunto - permitir que as mães e os bebês permaneçam juntos 24 horas por dia; Passo 8 . Encorajar o aleitamento sob livre demanda; Passo 9. Não dar bicos artificiais ou chupetas a crianças amamentadas ao seio e Passo 10. Encorajar a formação de grupos de apoio à amamentação para onde as mães devem ser encaminhadas, logo após a alta do hospital ou ambulatório.

Analisando o comportamento regional, observase na Tabela 2, que os passos três, quatro, cinco e sete não foram cumpridos por alguns hospitais da região Centro-Oeste, especificamente no Distrito
Federal, onde o passo cinco não foi cumprido por um HAC, o passo quatro por três HAC e os passos três e sete por um HAC.

Tabela 2

Cumprimento dos "Dez Passos para o Sucesso do Aleitamento Materno". Número de hospitais por Estados da Região Centro-Oeste, Nordeste e Sudeste.

\begin{tabular}{|c|c|c|c|c|c|c|c|c|c|c|c|}
\hline \multirow{2}{*}{ Estado/Região } & \multicolumn{10}{|c|}{ Passos } & \multirow{2}{*}{$\begin{array}{c}\text { Hospitais Amigos da Criança avaliados } \\
\text { Total }\end{array}$} \\
\hline & 1 & 2 & 3 & 4 & 5 & 6 & 7 & 8 & 9 & 10 & \\
\hline Centro-Oeste & 18 & 18 & 17 & 15 & 17 & 18 & 17 & 18 & 18 & 18 & 18 \\
\hline Distrito Federal & 10 & 10 & 9 & 7 & 9 & 10 & 9 & 10 & 10 & 10 & 10 \\
\hline Goiás & 8 & 8 & 8 & 8 & 8 & 8 & 8 & 8 & 8 & 8 & 8 \\
\hline Nordeste & 74 & 70 & 74 & 76 & 69 & 75 & 76 & 74 & 74 & 69 & 76 \\
\hline Bahia & 6 & 6 & 6 & 6 & 6 & 6 & 6 & 6 & 6 & 6 & 6 \\
\hline Ceará & 17 & 16 & 17 & 19 & 17 & 19 & 19 & 17 & 18 & 17 & 19 \\
\hline Maranhão & 10 & 10 & 10 & 10 & 10 & 9 & 10 & 10 & 10 & 10 & 10 \\
\hline Paraíba & 12 & 12 & 12 & 12 & 12 & 12 & 12 & 12 & 12 & 12 & 12 \\
\hline Pernambuco & 8 & 8 & 8 & 8 & 8 & 8 & 8 & 8 & 8 & 8 & 8 \\
\hline Piauí & 5 & 5 & 5 & 5 & 5 & 5 & 5 & 5 & 5 & 5 & 5 \\
\hline Rio Grande do Norte & 16 & 13 & 16 & 16 & 11 & 16 & 16 & 16 & 15 & 11 & 16 \\
\hline Sudeste & 21 & 21 & 21 & 20 & 20 & 19 & 21 & 21 & 21 & 20 & 21 \\
\hline Espírito Santo & 1 & 1 & 1 & 1 & 1 & 1 & 1 & 1 & 1 & 1 & 1 \\
\hline Minas Gerais & 8 & 8 & 8 & 7 & 7 & 7 & 8 & 8 & 8 & 7 & 8 \\
\hline Rio de Janeiro & 6 & 6 & 6 & 6 & 6 & 5 & 6 & 6 & 6 & 6 & 6 \\
\hline São Paulo & 6 & 6 & 6 & 6 & 6 & 6 & 6 & 6 & 6 & 6 & 6 \\
\hline Total de Hospitais Amigos da Criança & 113 & 109 & 112 & 111 & 106 & 112 & 114 & 113 & 113 & 107 & 115 \\
\hline
\end{tabular}

Passo 1. Ter uma norma escrita sobre aleitamento materno, que deverá ser rotineiramente transmitida a toda a equipe de cuidados de saúde; Passo 2. Treinar toda a equipe de cuidados de saúde, capacitando-a para implementar esta norma; Passo 3 . Informar todas as gestantes sobre as vantagens e o manejo do aleitamento; Passo 4. Ajudar as mães a iniciar a amamentação na primeira meia-hora após o parto; Passo 5. Mostrar às mães como amamentar e como manter a lactação, mesmo se vierem a ser separadas de seus filhos; Passo 6 . Não dar a recém-nascidos nenhum outro alimento ou bebida além do leite materno, a não ser que seja indicado pelo médico; Passo 7 . Praticar o alojamento conjunto - permitir que as mães e os bebês permaneçam juntos 24 horas por dia; Passo 8 . Encorajar o aleitamento sob livre demanda; Passo 9. Não dar bicos artificiais ou chupetas a crianças amamentadas ao seio e Passo 10. Encorajar a formação de grupos de apoio à amamentação para onde as mães devem ser encaminhadas, logo após a alta do hospital ou ambulatório. 
Na região Norte apenas duas instituições foram avaliadas, uma no Pará e outra no Amazonas. O hospital do Amazonas, único no estado, não cumpriu seis dos "Dez Passos..." estabelecidos, a saber: passos um, dois, cinco, oito e dez.

Na Tabela 2 pode-se observar que o cumprimento dos "Dez Passos..." na região Nordeste do país foi de aproximadamente $91 \%$, sendo que os passos quatro e sete foram cumpridos por todos os HAC da região. Os demais passos apresentaram dificuldades no cumprimento nos estados do Ceará, Maranhão e Rio Grande do Norte. Vale ressaltar que nessa região encontravam-se, na época, 58\% dos HAC do Brasil.

Na região Sul, 95\% das instituições avaliadas cumpriram todos os "Dez Passos...;" da IHAC. Apenas o estado do Paraná apresentou, em dois hospitais, pendências no cumprimento de alguns dos "Dez Passos...;" da IHAC.

Na região Sudeste, $90 \%$ dos hospitais cumpriram os "Dez Passos..." Os passos um, dois, três, sete, oito e nove foram cumpridos em todos os HAC. O descumprimento ocorreu nos passos quatro, cinco, seis e dez. Os estados que apresentaram passos pendentes foram Minas Gerais e Rio de Janeiro, como pode ser visto na Tabela 2.

A observação em conjunto dos resultados, segundo a análise do cumprimento de cada passo nas regiões do país, revelou que o passo um apresentou descumprimento apenas na região Norte, e o passo dois, nas regiões Norte e Nordeste.

O passo três que trata da informação a todas as gestantes sobre as vantagens e o manejo do aleitamento materno, não foi cumprido por uma instituição do Distrito Federal.

Nas regiões Nordeste e Sudeste do país o passo quatro é cumprido por todos os HAC. Apenas três hospitais do Distrito Federal e um do Amazonas não cumpriram esse passo.

O passo cinco que dispõe sobre a orientação às mães sobre o posicionamento e pega corretos para amamentar e sobre a expressão manual do leite, se destacou, uma vez que todas as regiões apresentaram dificuldades no seu cumprimento, conforme pode ser visto na Tabela 3.

O não cumprimento do passo seis em alguns estados destaca também a continuidade de um problema antigo no país, que é a doação de substitutos do leite materno a maternidades e hospitais, realizada por empresas fornecedoras desses produtos. Foram encontrados hospitais reprovados nesse passo nos estados do Maranhão, Minas Gerais e Rio de Janeiro.

O passo sete, que trata da prática do alojamento conjunto, revelou um alto cumprimento nos vários estados avaliados, sendo que dos 137 HAC, apenas uma instituição no Distrito Federal não cumpriu esse passo.
Tabela 3

Percentual de hospitais conforme as regiões do Brasil que atenderam ao Passo 5, de 1999 a 2000.

\begin{tabular}{ll}
\hline Regiões & $\%$ \\
\hline Centro - Oeste & 94,0 \\
Norte & 50,0 \\
Nordeste & 91,0 \\
Sul & 95,0 \\
Sudeste & 95,0 \\
Brasil & 92,0 \\
\hline
\end{tabular}

O passo oito, que discorre sobre encorajar o aleitamento sob livre demanda, foi cumprido por todos os HAC das regiões Centro-Oeste, Sudeste e Sul do país, e não observado apenas em alguns hospitais das regiões Norte e Nordeste. O passo nove não foi cumprido apenas por dois HAC da região Nordeste.

De todas as regiões avaliadas, a que mais se destacou em relação ao cumprimento do Passo dez foi a região Centro-Oeste, apresentando $100 \%$ de adequação ao mesmo. Nos estados do Amazonas, Ceará, Rio Grande do Norte, Paraná e Minas Gerais encontraram-se hospitais que não cumpriram esse passo.

\section{Discussão}

Já existe um consenso, em todo o mundo, sobre os benefícios da amamentação natural, como forma ideal de alimentar a criança pequena, no entanto essa prática no Brasil está ainda muito longe dos índices recomendados pela Organização Mundial de Saúde, conforme Susin et al. ${ }^{11}$

A Pesquisa Nacional de Saúde e Nutrição (PNSN), realizada em 1989 mostrou que a incidência do aleitamento materno no país é alta, cerca de $97 \%$, no entanto o desmame ocorre muito precocemente, sendo de $43 \%$ aos três meses e de $61 \%$ aos seis meses de vida. 12

Os dados observados no estudo realizado pelo Ministério da Saúde em 25 capitais brasileiras e no Distrito Federal confirmam a tendência de crescimento da prática do aleitamento materno no país, no entanto o desmame precoce tem se mostrado ainda intenso, especialmente no primeiro mês de vida. Com 30 dias, apenas $53 \%$ das crianças brasileiras recebem leite materno de forma exclusiva, e a duração mediana do aleitamento materno exclusivo foi de 23 dias. 8,13 
Devido a esses fatores, entende-se que o momento de intervir e de apoiar as gestantes e mães é especialmente no pré-natal, no momento do parto e durante as duas primeiras semanas pós-parto. É nesse período que a mulher precisa de apoio e decide sobre a alimentação do seu filho.

Estudos realizados no Brasil e no Chile têm mostrado o impacto da IHAC no aumento da duração do aleitamento materno. No Chile, Valdez et al., 14 em 1993, acompanharam crianças nascidas em um HAC, comparando-as com outras que nasceram em um hospital tradicional, em Santiago. A prevalência do aleitamento materno exclusivo (AME) nos primeiros seis meses de vida foi de $66,8 \%$ naquelas que nasceram no HAC, contra $23,3 \%$ nas que nasceram no hospital tradicional. No Brasil, estudo semelhante comparando um HAC em Santos, SP, com outro hospital tradicional, que não tinha um programa de incentivo ao aleitamento materno, mostrou que a média de AME foi de 75 dias nas crianças nascidas no HAC, contra 22 dias nas que nasceram no hospital tradicional. 15,16

Por tudo isso a IHAC tem sido uma estratégia fundamental para orientar e apoiar a mulher, para que ela possa decidir pela prática do aleitamento materno exclusivo até os seis meses, e continuado até os dois anos de idade ou mais, e assim melhorar os índices de aleitamento materno no país.

Para alcançar esse objetivo, faz-se necessário, além da implementação das estratégias já existentes de promoção, proteção e apoio ao aleitamento materno, o estabelecimento e implantação de outras ações, sobretudo as de controle e avaliação, para garantir a qualidade e a continuidade das iniciativas implantadas.

O estabelecimento da IHAC e a implementação dos "Dez Passos..." trouxeram mudanças efetivas nas rotinas hospitalares no país, podendo ser essa estratégia vista como uma das mais relevantes para o sucesso do aleitamento materno. ${ }^{2}$

No entanto, desde 1992, quando foi credenciado o primeiro HAC e passados sete anos da "Iniciativa Hospital Amigo da Criança" no Brasil, nenhum hospital tinha sido submetido há algum processo de avaliação em relação ao cumprimento dos "Dez Passos..." da IHAC. Isto poderia dar margem a uma série de questões relacionadas à qualidade, a efetividade e a sustentabilidade dessa estratégia. Não havia evidências, até então, se os HAC continuavam a implementar os "Dez Passos..." com a qualidade desejada, visando a garantia do direito da criança de acesso ao leite materno.

Ter um processo de avaliação que responda a essa questão é de fundamental importância para que os gestores federais e estaduais da IHAC no país, Ministério da Saúde e Secretarias Estaduais de Saúde, possam tomar decisões informadas e consubstanciadas, visando apoiar os hospitais credenciados no que diz respeito à manutenção da qualidade e a sustentabilidade dos "Dez Passos..."

Evidências científicas tem mostrado o impacto positivo dos "Dez Passos..." da IHAC para o aumento da freqüência e da duração do aleitamento materno. ${ }^{17}$ Portanto, é de suma importância o estabelecimento de um processo de avaliação constante para a manutenção de rotinas e práticas que favoreçam o início e a continuidade do aleitamento natural

Nesse estudo de avaliação dos HAC no Brasil, utilizou-se o instrumento de pré-avaliação, por não existir, na época, instrumento apropriado para realizar a avaliação dos HAC. Esse instrumento, quando aplicado no processo de pré-avaliação, utiliza uma amostra aleatória de duas gestantes, três puérperas, e de dois profissionais da equipe de saúde, sendo um enfermeiro(a) e um chefe ou responsável pelo setor de Neonatologia.

Para a finalidade desse estudo ampliou-se o tamanho da amostra, para cinco gestantes, cinco puérperas e cinco profissionais de saúde, com o objetivo de melhorar a representatividade dos resultados. Já o questionário de avaliação global utiliza uma amostra bem maior de dez gestantes, dez puérperas de partos vaginais e bebês normais, cinco puérperas com bebês em cuidados especiais, cinco mães com partos cesáreos de bebês normais, e dez profissionais de saúde.

O questionário de pré-avaliação, diferentemente do formulário de avaliação global, não dispõe de informações sobre os dados gerais do hospital, como o tipo do hospital, se público, privado, hospital-escola, ou mesmo dados de censos hospitalares.

Por tratar-se de um instrumento mais simplificado de avaliação, o questionário de pré-avaliação é aplicado em um dia, enquanto para aplicação do formulário de avaliação global, são necessários dois dias intensos de trabalho, já que esse último inclui observações em áreas de cuidados especiais para recém nascidos, em berçários, em salas de parto, além de entrevistas detalhadas com profissionais de saúde, gestantes e puérperas, para averiguação de conhecimentos sobre aleitamento materno. Portanto, a principal limitação do formulário de pré-avaliação é não contemplar justamente essas últimas informações. Apesar disto, quando comparado ao questionário de avaliação global, ainda se constitui em uma ferramenta capaz de refletir se o hospital continua cumprindo ou não os "Dez Passos..." Isto devese ao fato de não se tratar de um instrumento que 
apenas resume opiniões de chefias de diversos setores do hospital, como acontece com o formulário de auto-avaliação, mas baseia-se em entrevistas diretas com amostras aleatórias de mães e de funcionários, além das observações específicas no alojamento conjunto e no pré-parto.

Por esse motivo, e considerando que a sua aplicação em um dia viabilizaria a realização orçamentária do projeto de avaliação de 137 HAC, a Área de Aleitamento Materno do Ministério da Saúde optou, entre os formulários existentes, pelo uso do formulário de pré-avaliação, para o processo de avaliação dos hospitais credenciados no país, sendo que os resultados apresentados indicam ter sido possível estabelecer um retrato preliminar da situação do cumprimento dos "Dez Passos" nos HAC no Brasil.

Os dados apresentados chamam a atenção para alguns fatos importantes, relacionados a alguns dos passos. O passo cinco revelou ser um dos passos de maior dificuldade de cumprimento, em todas as regiões avaliadas. Para que ele seja cumprido as mães devem receber orientações sobre como amamentar e como retirar o leite das mamas para dar aos filhos, para que a produção do leite não seja interrompida.

Algumas mães, principalmente as primíparas, precisam de ajuda para iniciar, com sucesso, a amamentação. A técnica da amamentação necessita ser aprendida. Muitas mães passam por períodos de separação de seus filhos por motivos de doenças ou mesmo de trabalho. É preciso ensinar e demonstrar a todas as mães, como ordenhar o leite materno quando necessário, orientando-as a oferecer esse leite aos bebês, em copinho, visando assim manter a lactação. ${ }^{2}$

Um estudo observacional realizado em 1994 por Lang et al. 18 indicou que ensinar as mães a como ordenhar seu leite e como alimentar seus bebês com copinho pode aumentar o sucesso posterior da amamentação de bebês prematuros e doentes.

O ensino das técnicas de pega e posição corretas, de retirada do leite das mamas e de armazenagem do produto, deve ser estendido a todas as mães, para que em meio a qualquer intercorrência, possam fazêlo adequadamente, assim como para efeito de doação. Esse passo é portanto de fundamental importância para a continuidade do aleitamento materno exclusivo até os seis meses.

O passo dois, relativo ao treinamento de toda equipe de cuidados de saúde, capacitando-os para implementação da norma, também apresentou muitas dificuldades no seu cumprimento. Esse passo é essencial para o cumprimento dos demais. Somente profissionais treinados com o curso de 18 horas da IHAC ou com o curso de aconselhamento em ama- mentação, podem oferecer às gestantes e puérperas orientação e apoio efetivo.

O treinamento em serviço é obrigatório e deve ser apoiado pelas chefias. Quando o treinamento é voluntário e as chefias são descompromissadas, o comparecimento ao treinamento tende a ser fraco, e apenas os indivíduos de atitude favorável ao aleitamento materno participarão. 19,20

O treinamento deve ser continuado, considerando sobretudo, a existência de alta rotatividade de profissionais e de pessoal de saúde em alguns hospitais, especialmente nos hospitais universitários. $\mathrm{O}$ cumprimento constante desse passo é importante para assegurar as mudanças nas práticas hospitalares que visem a promoção, a proteção e o apoio a amamentação.

Um hospital que se preocupa com a promoção e proteção ao aleitamento materno, deve, também, apoiar a continuidade da amamentação além de suas portas, por meio do encaminhamento das lactantes para grupos de apoio à amamentação. Esse é o objetivo do passo dez, que infelizmente ainda não esta sendo efetivado em todos os HAC do país.

A implantação de um projeto, elaborado pela Área Técnica de Aleitamento Materno da Saúde da Criança do Ministério da Saúde nos anos de 2001 e 2002, referente à "Iniciativa Unidade Básica Amiga da Amamentação" (IUBAAM), quando aprovada, se traduzirá em mais uma estratégia de promoção, proteção e apoio ao aleitamento natural. Tal ação, baseada na IHAC, também é constituída por "Dez Passos...", que deverão ser cumpridos pelas Unidades Básicas candidatas a essa "Iniciativa Unidade Básica Amiga da Amamentação".

Uma das grandes vantagens da implantação da IUBAAM é o apoio a IHAC por meio da adoção de medidas que fortaleçam as orientações no pré-natal sobre a importância e vantagens do aleitamento materno, e o manejo da lactação (passo três da IHAC), ampliando também o grupo de apoio às mães e seus familiares, potencializando assim o cumprimento do Passo dez.

Com freqüência observa-se um grande declínio nas taxas de aleitamento materno, sobretudo do exclusivo, nas primeiras semanas ou meses após o parto. $2,8,13$ Como fisiologicamente a maioria das mães pode produzir quantidades de leites ajustadas às necessidades do bebê, é provável que uma falta de apoio contínuo seja o fator comum importante nesse processo. ${ }^{21}$ Portanto, observa-se a necessidade e a importância do estabelecimento de estratégias que dêem um suporte contínuo às mães após a alta hospitalar, para fortalecimento e manutenção da amamentação. 
Estudos têm demonstrado que mães que receberam orientação sobre aleitamento materno no prénatal apresentaram maior conhecimento quando comparadas com o grupo que não recebeu orientação, e esse maior conhecimento foi associado com a decisão da mãe de amamentar. ${ }^{22}$ Entre primíparas, a taxa de amamentação exclusiva, nos três primeiros meses do bebê, foi significativamente maior entre as gestantes que receberam orientação sobre aleitamento materno. 23

A análise dos HAC que apresentaram pendências no cumprimento dos "Dez Passos para o Sucesso do Aleitamento Materno", indica que a grande maioria, ou seja, 73,7\% desses hospitais, foram credenciados antes de 1997, revelando que, como esses hospitais não eram submetidos a processos de avaliação, com o passar do tempo, alguns dos "Dez Passos..." da IHAC, foram deixando de serem cumpridos.

Esse fato sugere a necessidade de realização de avaliações periódicas nos hospitais credenciados, de forma a se promoverem as correções dos problemas detectados, bem como, o estímulo a manutenção do cumprimento dos "Dez Passos..." ao longo dos anos, gerando assim o contínuo desenvolvimento e a solidificação da IHAC no país.

A avaliação periódica destes passos é da maior relevância, uma vez que evidências científicas já comprovaram o impacto dos "Dez Passos..." sobre o aumento da frequiência e da duração do aleitamento materno.2,24 A manutenção de práticas hospitalares comprovadamente prejudiciais ao início do aleitamento materno bem sucedido não pode ser aceita, sendo que estas práticas assistenciais necessitam ser avaliadas sistematicamente, visando sua maior adequação, e conseqüentemente, o fortalecimento da IHAC. 17

\section{Conclusões}

O processo de avaliação da "Iniciativa Hospital Amigo da Criança", realizado pela primeira vez no Brasil nos anos de 1999 e 2000, utilizando o instrumento de pré-avaliação, mostrou que $92 \%$ dos HAC estudados continuavam cumprindo todos os "Dez
Passos para o Sucesso do Aleitamento Materno" preconizados pela UNICEF e a OMS.

Apesar da grande maioria dos HAC estarem cumprindo integralmente os "Dez Passos..." no país, alguns HAC estavam apresentando dificuldades, especialmente no cumprimento do Passo 5: "Mostrar às mães como manter a lactação, mesmo se vierem a ser separadas de seus filhos", Passo 10: "Formação de grupo de apoio" e do Passo 2: "Treinamento de toda a equipe de cuidados de saúde".

É importante salientar que nesse estudo de avaliação de HAC, não houve nenhum caso de descredenciamento por descumprimento de mais de seis passos, conforme previsto originalmente na avaliação.

A IHAC, por meio do cumprimento dos "Dez Passos..." tem contribuído fortemente para o estabelecimento da prática da amamentação e para a melhoria dos índices de aleitamento materno.

Para que os "Dez Passos..." da IHAC sejam cumpridos ao longo dos anos, faz-se necessário estabelecer um processo regular de reavaliações, uma vez que esta sistemática pode melhorar a qualidade da assistência ao binômio mãe-filho, proporcionando também o fortalecimento do HAC perante a sociedade.

A implantação desse sistema de avaliação no Brasil, sem dúvida contribuirá para o fortalecimento tanto da humanização no atendimento, quanto do ensino e da prática referente à importância do aleitamento natural para gestantes, puérperas e profissionais de saúde.

Este estudo possibilitou uma primeira metodologia de análise do cumprimento dos "Dez passos para o Sucesso do Aleitamento Materno" nos "Hospital Amigo da Criança", indicando a necessidade de aperfeiçoamento da mesma, contribuindo assim para a implantação de um contínuo processo de avaliação no país.

Essa ação é fundamental para o monitoramento da situação dos hospitais credenciados no país, visando o conhecimento dos pontos positivos e das dificuldades encontradas, possibilitando, assim, os ajustes necessários e o aperfeiçoamento desse processo. 


\section{Referências}

1. OMS (Organização Mundial da Saúde). Proteção, promoção e apoio ao aleitamento materno: o papel especial dos serviços materno-infantis. Genebra: A Organização; 1989.

2. OMS (Organização Mundial da Saúde). Evidências científicas dos Dez Passos para o Sucesso do Aleitamento Materno. Brasília (DF): A Organização; 2001.

3. WHO (World Health Organization). The international code of marketing of breast-milk substitutes. Genebra: The Organization; 1981.

4. Lamounier JA. Experiência Iniciativa Hospital Amigo da Criança. Rev Assoc Med Bras 1998; 44: 319-24.

5. Lamounier JA, Maranhão AGK, Araújo MFM. A Iniciativa Hospital Amigo da Criança no Brasil. In: Rego JD. Aleitamento materno. São Paulo: Atheneu; 2001. p. 33342.

6. Giugliani ERJ. Amamentação: como e porque promover. J Pediatr [Rio de Janeiro] 1994; 70: 138-51.

7. Ministério da Saúde. Avaliação das ações executadas em aleitamento materno no ano de 2002: relatório. Brasília (DF): O Ministério; 2002.

8. Araújo MFM. Situação e perspectivas do aleitamento materno no Brasil. In: Carvalho MR, Tamez RN. Amamentação: bases científicas para a prática profissional. Rio de Janeiro: Guanabara Koogan; 2002. p. 1-10.

9. Ministério da Saúde. Portaria SAS n. ${ }^{\circ} 29$ de 22 de junho de 2001. Estabelece as normas para o processo de credenciamento e de descredenciamento dos Hospitais Amigo da Criança no País. DOU: Diário Oficial da União 2001 Jun 27; Seção 1, (123-E): 55.

10. Ministério da Saúde. Portaria n. ${ }^{\circ}$ 572/GM de 1 de junho de 2000.Humanização no pré-natal e nascimento. DOU: Diário Oficial da União 2000 jun 8; Seção 1 (110-E): 8.

11. Susin LROO, Giugliani ERJ, Kummer SC, Maciel M, Benjamin AC, Machado DB, Barcaro OM, Draghetti V. Uma estratégia simples que aumenta os conhecimentos das mães em aleitamento materno e melhora as taxas de amamentação. J Pediatr [Rio de Janeiro] 1998; 74: 368-76.

12. INAN (Instituto Nacional de Alimentação e Nutrição) Pesquisa Nacional de Saúde e Nutrição: 1989. Brasília (DF): O Instituto; 1989
13. Ministério da Saúde. Pesquisa de prevalência do aleitamento materno nas capitais e no Distrito Federal: relatório. Brasília (DF): O Ministério; 2001.

14. Valdez V, Perez A, Labbok M, Pugin E, Zambrano I, Catalan S. The impact of a hospital and clinic-based breastfeeding promotion programme in a middle class urban environment. J Trop Pediatr 1993; 39: 142-51.

15. Lutter C, Escamilla RP, Segall A, Sanghvi TG, Teruya K, Rivera A. Effect of hospital-based breastfeeding promotion programs on exclusive breastfeeding in three Latin American countries. Washington (DC): USAID, LAC; 1994. (Technical Report, 9).

16. Fiedler JL. Cost of the breastfeeding promotion program in the Guilherme Alvaro Hospital of Santos, Brazil. Washington (DC): USAID, LAC; 1995.

17. Venâncio SI. Dificuldades para o estabelecimento da amamentação: papel das práticas assistenciais das maternidades. J Pediatr [Rio de Janeiro] 2003; 79: 1-2.

18. Lang S, Lawrence CJ, Orme RLE. Cup feeding: an alternative method of infant feeding. Arch Dis Child 1994; 71: 365-9.

19. Stokamer CL. Breast feeding promotion efforts: why some do not work. Int J Ginecol Obst 1990; 31: 61-5.

20. Iker CE, Mogan J. Supplementation of breastfed infants: does continuing education for nurses make a difference? J Hum Lact 1992; 8: 131-5.

21. Woolridge MW. Problems of establishing lactation. Food Nutr Bul 1996; 17: 316-23.

22. Grossman LK, Harter C, Hasbrouck C. Testing mother's knowledge of breastfeeding: instrument development and implementation and correlation with infant feeding decision. J Pediatr Perinat Nutr 1990; 2: 43-63.

23. Jenner $\mathrm{S}$. The influence of additional information, advice and support on the success of breast feeding in working class primiparas. Child Care Health Dev 1988; 14: 31928.

24. Lamounier JA. Promoção e incentivo ao aleitamento materno: Iniciativa Hospital Amigo da Criança. J Pediatr [Rio de Janeiro] 1996; 72: 363-8.

Recebido em 9 de julho de 2003

Versão final reapresentada em 20 de outubro de 2003

Aprovado em 17 de novembro de 2003 